\title{
Farmers' perceptions, awareness, attitudes and adaption behaviour towards climate change
}

\section{Rulia Akhtar, Rafia Afroz, Muhammad Mehedi Masud, Mahfuzur Rahman, Haniza Khalid \& Jarita Binti Duasa}

To cite this article: Rulia Akhtar, Rafia Afroz, Muhammad Mehedi Masud, Mahfuzur Rahman, Haniza Khalid \& Jarita Binti Duasa (2018): Farmers' perceptions, awareness, attitudes and adaption behaviour towards climate change, Journal of the Asia Pacific Economy, DOI:

10.1080/13547860.2018.1442149

To link to this article: https://doi.org/10.1080/13547860.2018.1442149

冓 Published online: 27 May 2018.

Submit your article to this journal $\pi$

Џ Article views: 5

Q View related articles $₫$

View Crossmark data ־

4 Citing articles: 1 View citing articles 진 


\title{
Farmers' perceptions, awareness, attitudes and adaption behaviour towards climate change
}

\author{
Rulia Akhtar ${ }^{\mathrm{a} *}$, Rafia Afroz ${ }^{\mathrm{a}}$, Muhammad Mehedi Masud ${ }^{\mathrm{b}}$, Mahfuzur Rahman (iD ${ }^{\mathrm{c}}$, \\ Haniza Khalid ${ }^{d}$ and Jarita Binti Duasa ${ }^{d}$ \\ ${ }^{a}$ Department of Economics, Faculty of Economics and Management Sciences, International Islamic University \\ Malaysia, Kuala Lumpur, Malaysia; ${ }^{b}$ Department of Development Studies, Faculty of Economics and \\ Administration, University of Malaya, Kuala Lumpur, Malaysia; 'Department of Finance and Banking, Faculty \\ of Business and Accountancy, University of Malaya, Kuala Lumpur, Malaysia; ${ }^{\mathrm{d}}$ Department of Economics, \\ Faculty of Economics and Management Sciences, International Islamic University Malaysia, Kuala Lumpur, Malaysia
}

\begin{abstract}
Using responses from a questionnaire survey conducted on a sample of 400 rice farmers from Kedah in Malaysia, this article examines rice farmers' perception, awareness, attitudes and adaptation behaviours towards mitigating climate change. The data collected was analysed using structural equation modelling. The findings of this study show that $84 \%$ of the respondents perceive a decrease in rainfall, while $75 \%$ perceive an increase in temperature over the last 10-15 years due to climate change. The study also finds a significant and positive association between farmers' perception of climate change, awareness (AWN), attitudes (ATT) and adaptation behaviour (ADB). Furthermore, the results reveal that awareness and attitudes play a mediating role between perception and adaptation behaviour. The findings could be useful to public and private organizations in learning more about farmers' perceptions and adaptation behaviour in developing a policy framework to reduce adverse effects of climate change.
\end{abstract}

\section{KEYWORDS}

Agriculture; adaptation; barriers; behaviour; climate change; perception

\section{Introduction}

Agriculture plays an important role in the economy of a country and the development of human civilizations. Structural economists argue that agriculture is among the primary sectors that initiate economic growth to support the emergence of the secondary and later the service sectors (Kaldor 1967; Rasiah 1993). Sedentary farming is the first human activity that is focused on land-based production of crops and animals for generating value added (Rubenstein 2003). More than half of the world's arable land is used for agricultural activities (Allajabou and Bello 2014). Agriculture also contributes significantly to food security, which is critical as the sustainable development goals (SDGs), among other things, focus on environmental sustainability to prevent hunger. However, the adverse

\footnotetext{
CONTACT Rulia Akhtar rulia.aktar@yahoo.com, rulia@um.edu.my

*Present Address: Visiting Research Fellow, Centre for Poverty and Development Studies (CPDS), Faculty of Economics and Administration, University of Malaya, Malaysia.
} 
effects of climate change and global warming have been impacting negatively on agricultural lands, which has raised uncertainty in the food supply chain, thereby threatening food security, particularly in tropical and subtropical regions (Al-Amin et al. 2011).

It has been observed that poor people tend to live in the rural areas of the developing countries where agriculture is the main livelihood. The Intergovernmental Panel on Climate Change (IPCC) recognizes that developing countries are more vulnerable to climate change than the developed countries owing to capital scarcity (Hertel and Lobell 2010; Tubiello and Rosenzweig 2008). According to IPCC, global crops such as corn, rice, wheat and cereal production will drop by $25 \%$ by the year 2050 (Rosegrant et al. 2014). Agriculture is also an important source of livelihood in South-East Asia, where 115 million hectares of land are used for cultivating rice, oil palm, corn, rubber and coconut (Weiss 2009). The effects of climate change is now threatening rice production in Asia with falling yields caused by floods and droughts (Masutomi et al. 2009).

Agriculture also plays an important role in Malaysia, albeit its share in GDP has fallen sharply to less than $10 \%$ by 2015 (Rasiah 2011). Most of the small-scale farmers largely depend on rice cultivation. There were about 296,000 rice producers in Malaysia with almost $40 \%$ of them are full-time farmers in 2010 (Firdaus, Latiff, and Borkotoky 2013). The numbers were bigger in the earlier years (Man and Sadiya 2009). There were eight main granaries and some small sheds throughout the peninsular Malaysia engaged in rice farming in 2010 (Fahmi, Samah, and Abdullah 2013). Malaysia had a self-sufficiency rate of around $73 \%$ in 2010 (Malaysia 2011). With climate change affecting yields, Malaysia's dependency on rice imports from other countries is likely to rise (Masud et al. 2014). Rice production in Malaysia has decreased over the years due to a decline in cultivated areas, low technical change and climate change (Alam et al. 2010). Hence, it is important to investigate farmers' perceptions, awareness, attitudes and adaptation behaviour towards climate change. Farmers' practices will form a major source of information that the government can use to address the falling productivity levels faced by rice farmers in Malaysia.

\section{Literature review}

Consequently, it is essential to explore farmers' perception and adaptation strategies on climate change to offer an informed framework for addressing climate change. The capacity of farmers to perceive the causes of climate change is a fundamental precondition for choosing adaptation strategies. Localized forms of perception of climate risk strongly depend on societal, ethnic and economic situations in which people experience risk as perceptions influence behaviour (Patt and Schröter 2008). A profound understanding of farmers' perception about climate change is significant for policy-makers when determining adaptation strategies (Antwi-Agyei, Dougill, and Stringer 2015). In order to explore the risk perception of farmers about climate change, this study applied the Health Belief Model (HBM) and the Theory of Planned Behaviour (TPB). HBM identified four psychological dimensions that are supposed to influence decisions of persons to adapt specific behaviours, such as perceived susceptibility, perceived severity, perceived benefits and perceived barriers (Simon and Das 1984).

Perceived susceptibility refers to a person's feeling of being affected by a particular problem such as climate change, which may lead to a greater change in attitudes (Dabbs and Leventhal 1966). Climate change poses a number of significant risks to the agro- 
economy (Georgescu, Lobell, and Field 2011; Lobell, Schlenker, and Costa-Roberts 2011). Climate-related natural disasters can affect crop productivity, such as rice, cereals, millet, palm oil and maize, which can lead to uncertainty in the nutrition chain and threaten food security in the future (Al-Amin et al. 2010). Thus, this negative impact of climate change might increase the feeling of being affected which will lead to a more attitudinal change (Dabbs and Leventhal 1966). Masud et al. (2015) found that consciousness, knowledge and risk perception of climate change have effects on the formation of favourable attitudes towards climate change. Bayard and Jolly (2007) found that a larger perception of susceptibility of soil degradation influences the farmers' awareness and attitudes towards environmental problems. The perception of the risk of environmental issues has positive and substantial influence on attitudes towards the environment (Brody, Demetriades, and Esplen 2008; Masud et al. 2015). It has also been found that perception of risk has an important impact on the likelihood of an individual practising pro-environmental behaviour (Marquit 2008). It was noted in previous research that those who have the perception of environmental degradation engage in environment-friendly activities (Brody, Demetriades, and Esplen 2008). This implies that good understanding of climate change by farmers can lead to appropriate adaptation practices.

Perceived severity refers to consciousness of the intensity of the problem (CEP). It may state the seriousness of the problems. If an individual is aware that environmental degradation could affect their livelihood, then definitely, it will help in the establishment of favourable attitudes. It was found that greater fear and perceived seriousness of a livelihood threat have been associated with a greater change in attitudes (Dabbs and Leventhal 1966; Leventhal, Singer, and Jones 1965; Hass, Bagley, and Rogers 1975). As Witte (1992, 1998) argued, the perceived risk is a combination of perceived susceptibility and severity. Perceived threat has emerged as a possible determinant to pro-environmental behaviours (e.g. Vining et al. 2002). Bayard and Jolly (2007) found that perceived severity of environmental degradation has a significant effect on attitudinal variables.

Benefits refer to the perceived economic and societal benefits of environmental development, and barriers are self-imposed psychological blockades and elements that can hinder positive actions. It is obvious that whenever people are aware of benefits of environmental improvement, it leads them to form favourable attitudes towards environment and practise adaptation behaviour. Maddison (2007) revealed that adaptation to climate change needs understanding of farmers' perception of the extent to which climate has already changed, and it needs to identify useful approaches in implementing the necessary adaptation responses. Novelli and Scarth (2007) argue that people are happier about the adaptation of climate change when they feel they are benefitting from it. Bayard and Jolly (2007) found that greater perception of economic and social benefits of environmental improvement has a significant impact on attitudinal factors.

Perceived barriers refer to self-imposed psychological blockades or components that might hinder positive actions. It means whenever an individual is going to take actions to environmental improvement might confront different barriers such as economic and social barriers. Scientific advice suggests that a farmer's ability to identify climate change is an essential prerequisite for choosing the issue of adaptation. To improve policy to address the challenges of climate change, it is important to have awareness of climate change, choice of methods for coping mechanism and its barriers to adaption. Adapting to climate change substantially cuts down the adverse effects of climate change as well as 
reduces susceptibilities and promotes sustainable growth by improving the well-being of the farmers and others (Smit and Pilifosova 2003). In fact, adaptation is a way of reducing vulnerability, increasing resilience and mitigating the danger of climate impacts on lives and livelihoods. There is no doubt that in order to minimize the impact of climate change on agriculture, farmers' perceptions of climate change and adaptation strategies need to be better understood. If there are social and economic barriers to adaptation to climate change, it could have an insignificant impact on farmers' awareness and adaptation practices. It was found by Bayard and Jolly (2007) that perception of economic and social barriers to climate change of adaptation has a negative influence on awareness and attitudinal factors.

Adaptation refers to adjustments in ecological, social, or economic systems in response to actual or expected climatic stimuli and their effects or impacts. It refers to changes in processes, practices, and structures to moderate potential damages or to benefit from opportunities associated with climate change. (IPCC 2001, Third Assessment Report)

If the expansion of a diagnostic framework is to succeed, it is important to specify what counts as 'adaptation' in order to delineate the actions and contexts in which obstacles may come up. Adaptation behaviour refers to real adjustments or changes in decision-making environments that could ultimately improve resilience or reduce susceptibility to observed or anticipated climate changes (Adger 2007). There is an urgent demand for adaptation behaviour research to develop cognitive, socio-psychological and behavioural challenges of human adaptive capacity, especially in the Malaysian agricultural sector due to its low resource and institutional adaptive capacity. Understanding farmers' knowledge on environmental issues is a crucial component for environmental protection. Understanding the farmers' views, attitudes and beliefs about environmental issues is essential for adaptation behaviours (Leiserowitz et al. 2013; Shome et al. 2009).

In order to have the adaptation behaviour of farmers, researchers must incorporate behaviour change theories, such as TPB and utility maximization theory, in their studies to improve their ability to predict the human behaviour to obtain positive results in terms of adaptation behaviour in the agricultural sector. Understanding individual self-efficacy levels, expectations from outcomes, perceived behavioural control, behavioural intentions and the individual's stage in the process of behaviour change are important for research and adaptation behavioural practice. This knowledge will assist decision-makers to present data in ways that increase individual confidence, provide motivation and rewards for action, and shape positive attitudes towards adaptation behaviour to climate change.

An individual behaviour is at the heart of the challenge of climate change because individuals are the drivers of broader change processes and make policy decisions (Liverani 2009). Consequently, factors persuading individual behaviour outside of market mechanisms are significant for climate change, and an emphasis on individual behaviour in scientific research is required to recognize issues that regulate climate-friendly behaviour and develop procedures to change behaviour. Therefore, one can perceive that awareness, perception and attitudes towards behaviour can lead to adaptation behaviour. Based on the above literature review, a total 11 hypotheses (see Table 6) were developed to test the proposed research framework (see Figure 1). 


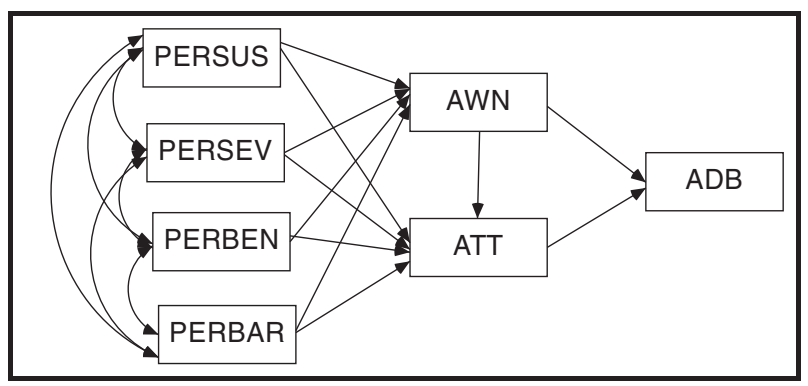

Figure 1. Research framework.

Source: Drawn from literature review. Legend: PERSUS = perceived susceptibility, PERSEV = perceived severity, PERBEN = perceived benefit, PERBAR = perceived barrier, $A T T=$ attitudes towards climate change, $A W N=$ awareness towards climate change, $\mathrm{ADB}=$ adaptation behaviour towards climate change and $A_{b}=$ adaptation activities are taken by farmers).

\section{Research framework}

In order to achieve the study objectives, we develop the following theoretical framework based on the literature review (see Figure 1), which was formulated based on HBM and the TPB. It shows the relationship between the variables. In order to test the empirical relationship between dependent and independent variables, structural equation modelling (SEM) was deployed, which can be formulated as follows:

$$
\begin{gathered}
\mathrm{ADB}=f(\mathrm{AWN}, \mathrm{ATT}) \\
\mathrm{AWN}=f(\text { PERSUS, PERSEV, PERBEN and PERBAR }) \\
\mathrm{ATT}=f(\text { PERSUS, PERSEV, PERBEN and PERBAR }) \\
A_{b}=A_{b}(\mathrm{AWN}, \mathrm{ATT} \text { and ADB }) \text { subject to (PERSUS, PERSEV, PERBEN and PERBAR) }
\end{gathered}
$$

\section{Method and data}

\subsection{Study area}

This study was conducted in the region administered by the Muda Agricultural Development Authority (MADA) in Kedah, Malaysia. Kedah is one of the most vulnerable states in terms of hardcore poverty due to climate change (NAHRIM 2006). The most vulnerable groups of people are engaged in agricultural activities, while the numbers are relatively large (NRS 2001). The region administered by MADA is the largest rice granary area of the country (Vaghefi et al. 2013). Approximately $76 \%$ of the land is under rice cultivation and around 55,000 farm families live there. It is also called 'Rice Bowl' of Malaysia.

\subsection{Sampling technique and sample size}

Using stratified proportionate random sampling technique, the entire study area was stratified into 27 PPK strata based on the homogeneous group with around 55,000 farmers. It is rationally challenging to consider all strata due to time and budget constraints. Hence, we selected seven strata (7 PPK) for this study. Since the population (number of farmers) is known, the following formula by Yamane (1967) was used to obtain the 
appropriate sample size from the population:

$$
n=N /\left(1+N d^{2}\right)
$$

where $n$ is the sample size, $N$ is the number of farmers (total population) and $d$ is the margin of error (0.05). The study area has a population of 55,000. Thus, we calculated a sample size of 397. In accordance with the guidelines recommended above, it was considered that the required sample size is 400 for this study.

\subsection{Questionnaire design}

During the development of the questionnaire, numerous questions concerning farmers' perception and adaptation to climate change were considered. The questionnaire consists of three sections. The first section contains respondents' demographic information, which included gender, age, education and income. The second section includes issues related to perception, causes of climate change, perceived importance of adaptation practices and barriers to adaptation, and the third includes the impact of risk perception on awareness, attitudes and coping behaviours. The constructions are measured using a five-point Likert-scale with strongly disagree and strongly in agreement (5). The questionnaires were distributed and collected as part of the face-to-face approach. The elements of the questionnaire were translated from English to Bahasa Malay to make accessible to all respondents.

\section{Results and analysis}

\subsection{Socio-economic characteristics of respondents}

The sample size of this study consists of $93 \%$ males and $7 \%$ females, as shown in Table 1 . The findings revealed that most of the farmers $(80.3 \%)$ are in age range between 51 and 65 years. It indicates that most of them are aged farmers. Younger generations are not interested in agriculture sector. Majority of the farmers have primary education (33\%), while $31.3 \%$ of the farmers have lower secondary education, and $27.3 \%$ of them have

Table 1. Socio-demographic information of the respondents.

\begin{tabular}{llcr}
\hline Basic information & \multicolumn{1}{c}{ Group } & No of respondents & Percentage \\
\hline Gender & Male & 370 & 92.5 \\
Age & Female & 30 & 7.5 \\
& $1=25$ years or below & 3 & 0.7 \\
& $2=26-30$ years & 8 & 2.0 \\
& $3=31-45$ years & 10 & 2.5 \\
Education level & $4=46-50$ years & 66 & 16.5 \\
& $5=51-65$ years & 321 & 80.3 \\
& No formal education & 35 & 8.75 \\
& Primary & & 32.5 \\
Income of household (RM/month) & Primary & 130 & 30.75 \\
& Lower secondary & 123 & 27.75 \\
& Higher secondary & 111 & 0.3 \\
& Diploma & 1 & 60.7 \\
& 2000 and less than 2000 & 243 & 35.0 \\
\hline
\end{tabular}


higher secondary education. The result also shows that majority of the farmers' income level is between less than RM 2000 and RM 2000, while only 35\% earn between RM 2001 and RM 4000.

\subsection{Farmers' general perceptions of climate change}

Most of the farmers (73\%) reported an increase in temperature over the last 10-15 years (Figure 3). Approximately $8.5 \%$ of respondents perceived no change, $15 \%$ were receiving a temperature drop and $3.5 \%$ did not know if there was a change in temperature over time. In general, farmers believe that the increasing temperature trend was linked with changes in rainfall. In total, $82.4 \%$ of respondents said that rainfall decreased over the last 10-15 years, $3.4 \%$ observed no change in rainfall and only $2 \%$ did not know about the increase or decrease in rainfall. The majority of the farmers mentioned that drought has increased by $78.4 \%$, while $95 \%$ confirm that the frequency of flood is increasing during the last decade. While $11 \%$ and $1.5 \%$ mentioned that there was no change in drought and flood (see Figure 2).

\subsection{Adaptation practices and adaptation barriers}

In this study, we attempted to explore farmers' current adaptation practices and to identify adaptation barriers. The results indicate that farmers currently take several adaptation practices in fighting against climate change which are shown in Table 2. Most of the farmers tried to improve their irrigation system while some of them cultivate drought-tolerant rice varieties and mixed cropping. The findings also revealed that farmers are confronting numerous challenges in terms of adaptation practices, for example, high cost of farm input, unpredictable weather, inadequate water supply, lack of information on weather condition and shortage of field officers, insufficient credit facilities and agricultural subsidies, as shown in Table 2.

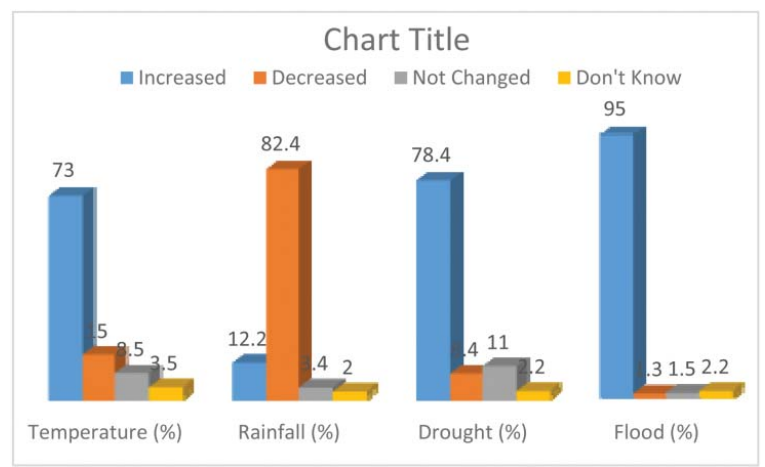

Figure 2. Perception of farmers about climate change.

Source: Authors estimation. 
Table 2. Adaptation techniques and barriers.

\begin{tabular}{lclc}
\hline Adaptation technique & $\%$ & \multicolumn{1}{c}{ Adaptation barriers } & $\%$ \\
\hline Improved irrigation & 28 & Unpredictable weather & 34 \\
Changing planting dates & 6 & Lack of access to water resources & 18 \\
Drought-tolerant rice varieties & 9 & Lack of access to timely weather information & 11 \\
Farming near water bodies & 4 & Deficiency of access to credit facilities & 7 \\
Use of organic fertilisers & 21 & Limited access to agricultural extension officers & 5 \\
Change farming location & 3 & Restricted access to agricultural subsidies & 9 \\
Change crop to livestock & 4 & Less access to agricultural markets & 7 \\
Crop varieties & 7 & Shortage of farm labour & 5 \\
Crop rotation & 5 & Poor soil fertility & 3 \\
Mixed cropping & 2 & Small farm size & 1 \\
\hline
\end{tabular}

\subsection{Impact of risk perception on awareness, attitudes and adaptation behaviour}

\subsubsection{Reliability analysis}

To determine the adequacy of internal consistency, the reliability analysis shows that all the Cronbach's alpha $(\alpha)$ coefficient values (see Table 3 ) are above the threshold value of 0.70 (Hair et al. 1998). It indicates that all constructs provide adequate coverage of the concepts, all elements are comprehensive and clear, and the questionnaire is a reliable measurement tool, suggesting sufficient internal consistency and reliability of the measurement scale. It states that all constructs provide adequate coverage of concepts; all elements are complete and clear. It indicates that questionnaire items are reliable and telling sufficient internal consistency.

\subsubsection{Tests for confirmatory factor analysis}

To confirm the composite reliability of all factors, convergent validity and discriminant, we carried out a confirmatory factor analysis (CFA). The results of the CFA test show that the seven variables have adequate moderate adjustment indices. It also confirmed that the normal value of the chi-square $\left(\chi^{2} / \mathrm{df}\right)$ was less than $\leq 3$; the CFI value is greater than the cut-off value of 0.90; and the RMSEA value is within the cut-off value of 0.08 , as shown in Table 4. The CFA also shows that all factor loads are between 0.657 and 0.950 . It indicates that all elements have a large element load greater than 0.50 , as shown in Table 4 . It confirms the existence of a discriminant and convergent validity.

\subsubsection{Convergent and discriminant validity}

Convergent validity is considered adequate when the average-extracted variance (AVE) is $\leq 0.50$. The standardized factor loadings of all elements were greater than 0.60 , range of between 0.657 and 0.950 , and were statistically significant at $1 \%$ level. This proof supports the uni-dimensionality of each scale, indicating that a convergent validity has been

Table 3. Reliability analysis.

\begin{tabular}{lccc}
\hline Constructs & Cronbach's alpha $(\alpha)$ & Mean & Std. dev. \\
\hline Perceived susceptibility & 0.904 & 3.9922 & .02310 \\
Perceived severity & 0.901 & 4.0982 & .02254 \\
Perceived benefit & 0.902 & 3.6050 & .03836 \\
Perceived barrier & 0.898 & 3.4803 & .03441 \\
Awareness towards climate change & 0.905 & 4.0296 & .02083 \\
Attitudes towards climate change & 0.900 & 3.4971 & .03303 \\
Adaptation behaviour to climate change & 0.902 & 3.7607 & .02379 \\
\hline
\end{tabular}


Table 4. Confirmatory factor analysis.

\begin{tabular}{|c|c|c|}
\hline $\begin{array}{l}\text { Fit indices for CFA measurement Model: Normed } \chi^{2}=2.953, C F I=0.901, \text { RMSEA }=0.074 \text {, } \\
\text { RMR }=0.067 .\end{array}$ & $\begin{array}{l}\text { Factor } \\
\text { loadings }\end{array}$ & SMC* \\
\hline \multicolumn{3}{|l|}{ Adaptation behaviour (ADB) } \\
\hline I encourage my neighbours' to adaptation climate change & 0.723 & 0.52 \\
\hline I am using organic fertilizers to increase the production & 0.875 & 0.76 \\
\hline I am trying to improve irrigation system in agriculture sector & 0.678 & 0.46 \\
\hline I am changing the location of farming' area & 0.729 & 0.53 \\
\hline \multicolumn{3}{|l|}{ Attitudes towards climate change (ATT) } \\
\hline Climate change is true & 0.657 & \\
\hline We should work to adapt climate change & 0.779 & 0.61 \\
\hline I am willing to take necessary actions to minimize the impact of climate change & 0.782 & 0.61 \\
\hline \multicolumn{3}{|l|}{ Awareness about climate change (AWN) } \\
\hline I am aware of climate change & 0.731 & 0.53 \\
\hline I am aware that climate change is a serious problem for rice production & 0.670 & 0.45 \\
\hline I am aware of climate change effects on agricultural sector & 0.732 & 0.53 \\
\hline \multicolumn{3}{|l|}{ Perceived susceptibility of climate change (PERSUS) } \\
\hline Climate change is a danger to public health & 0.770 & 0.60 \\
\hline Climate change impacts on agricultural production & 0.732 & 0.53 \\
\hline Frequency of flooding are causing crop damage & 0.784 & 0.61 \\
\hline \multicolumn{3}{|l|}{ Perceived severity of climate change (PERSEV) } \\
\hline Climate change can cause damages to human health & 0.705 & 0.50 \\
\hline Agricultural sector is affected by climate change & 0.731 & 0.53 \\
\hline Climate change can cause water scarcity & 0.729 & 0.53 \\
\hline \multicolumn{3}{|l|}{ Perceived benefits of adaptation (PERBEN) } \\
\hline Agricultural production will increase & 0.741 & 0.55 \\
\hline Standard of living will improve & 0.867 & 0.75 \\
\hline Adaptation will reduce the adverse effect of climate change & 0.950 & 0.90 \\
\hline \multicolumn{3}{|l|}{ Perceived barrier (PERBAR) } \\
\hline I have financial problem due to high cost of adaptation & 0.755 & 0.57 \\
\hline I do not get enough information about climate change adaptation & 0.899 & 0.80 \\
\hline Lack of irrigation system & 0.758 & 0.57 \\
\hline Unpredictable weather & 0.817 & 0.67 \\
\hline Lack of understanding of adaptation practices & 0.681 & 0.46 \\
\hline
\end{tabular}

${ }^{*}$ Squared multiple correlation.

attained. The composite reliability (CR) and the AVE were calculated according to the procedure described by Lowry and Gaskin (2014). The CR was found as PERSUS (0.717), PERSEV (0.750, PERBEN (0.854), PERBAR (0.904), AWN (0.742), ATT (0.812) and ADB (0.792). According to Hair et al. (1998), Malhotra and Birks (2006) and Sekaran (2003), the minimum acceptable reliability value is 0.70 . Once the convergent validity was obtained, it was appropriate to test the validity of the discriminant. The discriminative validity was present when the correlation between two constructions was less than the recommended value $(r \leq 0.85)$ representing the existence of a discriminating validity (see Table 5) (Kline 2010).

\subsubsection{Structural equation modelling framework}

The SEM examined the relationship between climate change perception, attitudes to climate change, climate change awareness and adaptation behaviour. The complete structured model presents a satisfactory quality of fit with the relative value of CMIN/df chisquare of 3.010, RMSEA of 0.078 , CMA of 0.055 , GFI of 0.914 , NFI of 0.890 and CFI of 0.936 . As shown in Figure 3, the $R^{2}$ for AWN was $45 \%$, indicating that all variables studied contributed to approximately $45 \%$ of the variance explained in AWN. On the other hand, the $R^{2}$ for ATT was $64 \%$, indicating that all the little-studied variables contributed to about $64 \%$ of the variance explained in ATT. In addition, the $R^{2}$ for the ADB was $41 \%$ 
Table 5. Convergent and discriminant validity.

\begin{tabular}{lccccccccr}
\hline & CR & AVE & AWN & PERSUS & PERSEV & PERBEN & PERBAR & AT & ADB \\
\hline AWN & 0.742 & 0.579 & $\mathbf{0 . 7 6 0}$ & & & & & & \\
PERSUS & 0.717 & 0.560 & 0.552 & $\mathbf{0 . 7 4 9}$ & & & & & \\
PERSEV & 0.750 & 0.513 & 0.295 & 0.640 & 0.716 & & & & \\
PERBEN & 0.854 & 0.598 & 0.245 & 0.600 & 0.102 & 0.773 & & & \\
PERBAR & 0.904 & 0.613 & 0.383 & 0.545 & 0.036 & 0.567 & 0.783 & & \\
AT & 0.812 & 0.594 & 0.176 & 0.273 & 0.272 & 0.650 & 0.778 & 0.771 & \\
ADB & 0.792 & 0.562 & 0.230 & 0.081 & 0.269 & 0.397 & 0.683 & 0.730 & $\mathbf{0 . 7 4 9}$ \\
\hline
\end{tabular}

Legends: PERSUS = Perceived susceptibility, PERSEV $=$ Perceived severity, PERBEN = Perceived benefit, PERBAR $=$ Perceived barrier, $A W N=$ Awareness of climate change, $A T T=$ Attitudes towards climate change, $A D B=$ Adaptation behaviour towards climate change.

Note: Diagonal elements are in bold are the square root of the average variance extracted (AVE). Off-diagonal elements are the correlations among the constructs. For discriminate validity, diagonal elements should be larger than offdiagonal elements (Chiu and Wang 2008).

cent, indicating that all the variables contributed about $41 \%$ of the variance explained in the ADB.

Figure 3 and Table 6 present the output of the complete structural model. The results revealed that perceived susceptibility, perceived severity and perceived benefits have significant influence on awareness of climate change with $\beta=0.38,0.21,0.29$, respectively, at $1 \%$ significant level. It is also found that perceived barriers have negative impact on awareness of climate change as we expected with $\beta=-0.14$ at $p<0.910$. The results also revealed that perceived susceptibility, perceived severity and perceived benefits have significant influence on attitudes towards climate change with $\beta=0.27,0.22,0.38$, respectively, at $1 \%$ significant level. It is also found that perceived barriers have negative impact on attitudes towards climate change as we expected with $\beta=-0.07$ at $p<0.815$. This finding is consistent with the findings of Bayard and Jolly (2007) who found a significant relationship among those variables. For instance, if an individual has a feeling of being affected by environmental degradation, this feeling may lead to a greater attitudinal change. This change will help them to form favourable attitudes towards environmental behaviour. Thus, these results support $\mathrm{H} 1, \mathrm{H} 2, \mathrm{H} 3, \mathrm{H} 4, \mathrm{H} 5, \mathrm{H} 6, \mathrm{H} 7$ and $\mathrm{H} 8$.

The results revealed that awareness of climate change has influence on forming favourable attitudes towards climate change adaptation with $\beta=0.30$ at $1 \%$ significant level. It is

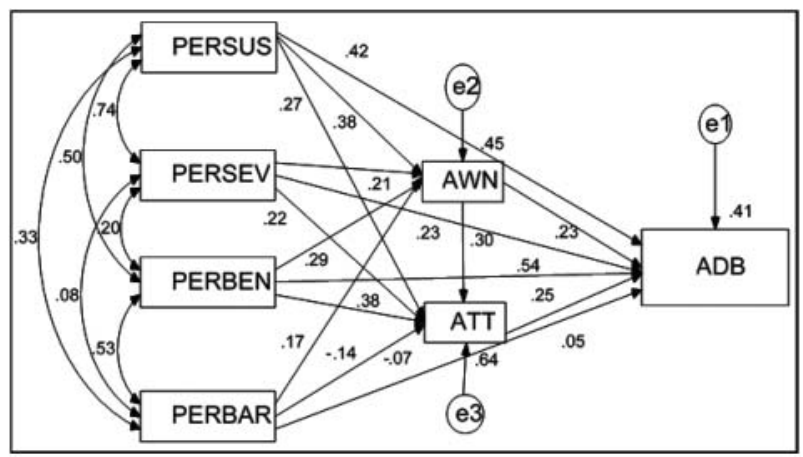

Figure 3. Full structural equation modelling.

Source: Authors estimation. 
Table 6. Hypothesis path coefficients.

\begin{tabular}{|c|c|c|c|c|}
\hline No. & Hypotheses & Coefficient $(\beta)$ & C.R & Remark \\
\hline $\mathrm{H} 1$ & Perceived susceptibility has influence on awareness of climate change. & $0.383^{* * *}$ & 3.538 & Supported \\
\hline $\mathrm{H} 2$ & Perceived severity has impacts on awareness of climate change. & $0.212^{* * *}$ & 5.380 & Supported \\
\hline $\mathrm{H3}$ & Perceived benefits has influence on awareness of climate change. & $0.293^{* * *}$ & 2.310 & Supported \\
\hline $\mathrm{H} 4$ & Perceived barriers has influence on awareness of climate change. & -0.142 & 0.910 & Supported \\
\hline H5 & Perceived susceptibility has influence on attitudes towards climate change. & $0.271^{* * *}$ & 3.076 & Supported \\
\hline $\mathrm{H} 6$ & Perceived severity has influence on attitudes towards climate change. & $0.223^{* * *}$ & 2.698 & Supported \\
\hline H7 & Perceived benefits has influence on attitudes towards climate change. & $0.385^{* * *}$ & 2.668 & Supported \\
\hline $\mathrm{H} 8$ & Perceived barriers has influence on attitudes towards climate change. & -0.071 & 0.815 & Supported \\
\hline $\mathrm{H} 9$ & $\begin{array}{l}\text { There is a significant positive relationship between awareness of climate } \\
\text { change and attitudes towards adaptation behaviour. }\end{array}$ & $0.302^{* * *}$ & 2.251 & Supported \\
\hline $\mathrm{H} 10$ & $\begin{array}{l}\text { There is a significant positive relationship between awareness and } \\
\text { adaptation behaviour towards climate change. }\end{array}$ & $0.231^{* * *}$ & 5.479 & Supported \\
\hline $\mathrm{H} 11$ & $\begin{array}{l}\text { There is a significant positive relationship between attitudes and adaptation } \\
\text { behaviour towards climate change. }\end{array}$ & $0.254^{* * *}$ & 4.691 & Supported \\
\hline
\end{tabular}

Note: ${ }^{* * *},{ }^{* *}$ and ${ }^{*}$ indicate $1 \%, 5 \%$ and $10 \%$ levels of significance, respectively.

also found that awareness and attitudes towards climate change influence adaptation behaviour with $\beta=0.23,0.25$ at $1 \%$ significant level. Therefore, these results support H9, $\mathrm{H} 10$ and H11.

Finally, the results also revealed that perceived susceptibility, perceived severity and perceived benefits have direct significant influence on adaptation behaviour with $\beta=0.42$, $0.23,0.54$, respectively, at $1 \%$ significant level, while perceived barriers have direct positive but insignificant influence on adaptation behaviour with $\beta=0.05, p<0.703$. These results are consistent with previous studies of Bayard and Jolly (2007), Sia, Hungerford, and Tomera (1985), Vaske and Kobrin (2001), because the environmental concern was a strong predictor of adaptation behaviour. In the test of mediating effects between perceived susceptibility, perceived severity, and perceived benefits and adaptation behaviour, we found there is a partial mediation effect of awareness and attitudes with $\beta=0.42,0.23$, 0.54 , respectively, at $1 \%$ significant level as shown in Table 7 . The results are consistent with the previous studies of Cottrell (2003), Bayard and Jolly (2007) and Masud et al. (2014).

\section{Conclusion and policy implications}

This study found perceived susceptibility, perceived severity and perceived benefits of climate change to play an important role in raising farmers' awareness of climate change

Table 7. Output of direct and mediating relationship.

\begin{tabular}{|c|c|c|c|c|c|c|}
\hline \multicolumn{3}{|c|}{ Direct relationship } & \multicolumn{3}{|c|}{ Relationship with mediator } & \multirow[b]{2}{*}{ Effects } \\
\hline & Estimate & $P$-Value & & Estimate & $P$-Value & \\
\hline \multirow[t]{2}{*}{ PERSUS-ADB } & 0.422 & 0.000 & PERSUS-AWN-ADB & 0.384 & 0.000 & Partial mediation \\
\hline & & & PERSUS-ATT-ADB & 0.273 & 0.000 & \\
\hline \multirow[t]{2}{*}{ PERSEV- ADB } & 0.232 & 0.000 & PERSEV-AWN-ADB & 0.213 & 0.000 & Partial mediation \\
\hline & & & PERSEV-ATT-ADB & 0.229 & 0.000 & \\
\hline \multirow[t]{2}{*}{ PERBEN-ADB } & 0.548 & 0.000 & PERBEN-AWN-ADB & 0.297 & 0.000 & Partial mediation \\
\hline & & & PERBEN-ATT-ADB & 0.381 & 0.000 & \\
\hline \multirow[t]{2}{*}{ PERBAR-ADB } & 0.058 & 0.703 & PERBAR-AWN-ADB & -0.145 & 0.910 & No effect \\
\hline & & & PERBAR-ATT-ADB & -0.072 & 0.815 & \\
\hline AWN-ATT & 0.097 & 0.017 & AWN-ATT-ADB & 0.097 & 0.000 & Partial mediation \\
\hline
\end{tabular}


and the formation of favourable attitudes in minimizing its adverse effects. The results were consistent with the study done by Bayard and Jolly (2007) who found a significant influence of perception of climate change on the attitudinal factors. The results of this study provide the empirical support that is similar to Le Dang, Li, Bruwer, and Nuberg (2014) who also noted that the farmers' perception of climate change was related to their adaptation behaviour. Based on this, it can be deduced that if people feel that they are being affected by an environmental problem such as environmental degradation, they would also feel that their livelihoods might be affected. Similarly, if they find that they would be able to acquire economic and social benefits by making environmental improvement then this may lead to a greater change in their attitude (Bayard and Jolly 2007).

This study also addressed the mediating effects between climate change awareness and attitudes towards climate change and between perception and adaptation behaviours. The outcome drawn from this study is consistent with the study done by Masud et al. (2016) and Bayard and Jolly (2007). It appears that proper perceptions can change beliefs. Therefore, beliefs can change attitudes towards taking actions (Kruglanski and Stroebe 2005) and behavioural decisions (McCown 2005). A good understanding of the environmental attitudes of mankind can be used to shape human behaviour and this can help the country to achieve a minimum level of adaptation to the changing climate conditions that are beyond the regional context (Rogers et al. 2011) and over time (Stern and Dietz 1994).

Furthermore, this study also found several barriers associated with adaptation practices, such as the high cost of farm input, unpredictable weather, lacking of water resources, unpredictable weather pattern, inadequate agricultural extension officers, the limited access to credit facilities and shortage of agricultural subsidies. This means that the existing farmers confront many difficulties in their adaptation practices. To overcome these barriers, policy-makers should consider developing an appropriate adaptation policy framework for the agriculture sector. Several steps taken by the farmers in adapting to the impact of climate change, as shown in this study, showed that majority followed a decreased water conservation technique, increased irrigation, and adjustment to livestock management, different planting dates and crop diversification. Farmers, particularly those in developing countries like Malaysia and Asia, need to adapt to climate change to reduce their negative impacts to gain the benefits of adaptation. It is right time to improve farmers' knowledge of climate change adaptation and to enable them to follow an appropriate adaptation mechanism to combat the negative impact of climate change. This could be achieved by establishing training activities, developing vocational training and increasing the capacity of others to enhance the adaptive capacity of farmers. These programmes are important not only for farmers, but also for government officials who provide the appropriate technical support to farmers.

\section{Conclusions and policy implications}

The findings of this study offer several implications for adaptation to address climate change for farmers in Malaysia. Unlike other studies that have focused on single disciplinary determinants, this study combined psychosocial and economic factors to obtain a broader assessment of climate change. This model also consists of limitations and barriers for it to be adequately adapted to the agricultural systems. To address the social aspects of climate change vulnerability, a local agenda for the adaptation of rice farmers should be 
developed. This should target the needs of the vulnerable farmers. Investments into the 'no-regret' options such as new crop varieties, climate smart extension services, climate change ready agronomic practices and livelihood supports, could be introduced.

However, the above initiatives need to be sensitive to the everyday lives of the farmers. Farmers should directly engage the coordinating authorities in their adaptation planning and decision-making. The IPCC Fifth Assessment Report noted the importance of engaging rural people in decision-making, especially to understand adaptation and the interplay of informal public decision-making. Farmers need to have a strong voice in the adaptation processes so that they can articulate their concerns and priorities effectively. There is also a need to proactively engage subnational actors in the adaptation planning and policy, and this can include the supporting subnational networks. Policy-makers can increase their outreach to other local stakeholders so as to increase an awareness of these policies and plans, thereby providing opportunities for feedback. Malaysia needs to build a public support for adaptation because this is generally, lacking in ASEAN countries. One key strategy to build a public support for adaptation is to engage smallholders in the adaptation planning process.

Similarly, as a matter of urgency, policy-makers should conduct the planning and carry out the adaptation strategies to minimize the adverse effects of the dynamic behaviour of climate change. The coping mechanisms must be designed in several agro-ecologies to establish some restraints on the boundaries and perspectives of each agro-ecology, as opposed to a specific affiliation. These strategies ought to be coordinated with the various industries. The outcome should also include making an investment in technology, which can improve the irrigation system, plant tolerance to droughts and early rice cultivation sessions, institutional capacity building, research, training and the promotion of farmers.

Furthermore, by increasing banking facilities to farmers and by providing relevant social services to farmers, agricultural activity in the rural areas can become more attractive and this can motivate farmers to pursue farming. The farmers of this study are clearly making efforts to adapt to climate change in various ways such as by using improved irrigation systems, by changing planting dates, by using formal irrigation systems by farming near water bodies, by using organic fertilizers, by shortening growing periods and by using other crop varieties. However, it appears that they lack adequate information on how to adapt to climate change. Therefore, it is recommended that the government provides a small-scale irrigation project that would minimize this stress. There should also be policies formulated to consider farmers' experiences with climate change and so it is suggested that such policies should be reliable and can effectively measure the adaptation that needs to be implemented. It seems clear that farmers should be given more support by local NGOs and the government, terms of trainings, information and knowledge sharing, and other fundamental resources which are necessary in their farming system.

In addition, these bodies should also consider providing technical training, particularly agricultural extension, and vocational training, to equip rural youths with the basic agricultural skills and knowledge to enable them to handle new technologies and technical software packages. There is certainly, a need for proper education and awareness building on the correct adaptation strategies. Furthermore, farmers should also adjust their planting dates to avoid crop failures due to late onset and early cessation of rains. Extension workers should be trained in the science of climate change to enable them to disseminate adequate information to farmers on appropriate adaptation measures. Finally, the 
government and private sectors should create small rural industries based on the currently available agricultural commodities (raw materials) to absorb rural youths into the labour force. This can motivate and encourage more young people to be involved in farming.

\section{Disclosure statement}

No potential conflict of interest was reported by the authors.

\section{Funding}

The authors would like to acknowledge the International Islamic University, Malaysia, for funding of 'Developing an Integrated Waqf Environmental Protection Model for Malaysian Rice Farmers' [grant number FRGS15-180-0421].

\section{Notes on contributors}

Rulia Akhtar obtained her doctorate from the Faculty of Economics and Management sciences, International Islamic University. She specializes in environmental economics, environmental impact assessment, climate change adaptation and mitigation, and disaster management.

Rafia Afroz is an assistant professor at the Faculty of Economics and Management Sciences, International Islamic University Malaysia. She obtained her doctorate from University Putra Malaysia in 2004.

Muhammad Mehedi Masud is a senior lecturer at the Faculty of Economics and Administration, University of Malaya. He specializes in environmental and sustainable development, environmental impact assessment, ecotourism development, climate change adaptation and mitigation, community development, livelihoods, poverty and social mobility. Among his awards include Academic Excellence Award (2014 and 2015).

Mahfuzur Rahman studies the relevance of psychological biases in individual investment behaviour. He models behavioural factors in investigating financial decision-making, financial risk tolerance and portfolio diversification. He teaches corporate finance, advanced managerial finance, financial management, financial markets and institutions, and macroeconomics.

Haniza Khalid is an assistant professor at the Faculty of Economics and Management Sciences, International Islamic University Malaysia. She obtained her doctorate from the University of Nottingham. She specializes in institutions and market forces in society's development, rural-urban welfare programmes using conventional and Islamic perspectives.

Jarita Duasa is a professor at the Faculty of Economics and Management Sciences, International Islamic University Malaysia. She obtained her doctorate from University of Sheffield. She is the recipient of the 2006 Quality Award, and 2011 Outstanding Social Sciences and Humanities award.

\section{ORCID}




\section{References}

Adger, D. 2007. "Variability and Modularity: A Response to Hudson." Journal of Linguistics 43 (3): 695-700.

Alam, M., C. Siwar, M. Murad, R. I. Molla, and M. E. B. Toriman. 2010. "The Relationships between the Socio-Economic Profile of Farmers and Paddy Productivity in North-West Selangor, Malaysia." Asia-Pacific Development Journal, United Nations Economic and Social Commission for Asia and the Pacific (ESCAP) 18 (1): 161-173.

Al-Amin, A. Q., M. N. Azam, M. Yeasmin, and F. Kari. 2010. "Policy Challenges Towards Potential Climate Change Impacts: In Search of Agro-Climate Stability." Scientific Research and Essays 5 (18): 2681-2685.

Al-Amin, A. Q., W. Leal, J. M. De la Trinxeria, A. H. Jaafar, and A. Z. Ghani. 2011. Assessing the Impacts of Climate Change in the Malaysian Agriculture Sector and its Influences in Investment Decision. Middle-East Journal of Scientific Research 7 (2): 225-234.

Allajabou, H. A., and A. R. S. Bello. 2014. "Rural Youth and Agriculture 'Problem' in Sudan: A case from the Nuba Mountains." World Rural Observations 6 (4): 1-12.

Antwi-Agyei, P., A. J. Dougill, and L. C. Stringer. 2015. "Barriers to Climate Change Adaptation: Evidence from Northeast Ghana in the Context of a Systematic Literature Review." Climate and Development 7 (4): 297-309.

Bayard, B., and C. Jolly. 2007. "Environmental Behavior Structure and Socio-economic Conditions of Hillside Farmers: A Multiple-Group Structural Equation Modeling Approach.” Ecological Economics 62 (3): 433-440.

Brody, A., J. Demetriades, and E. Esplen. 2008. Gender and Climate Change: Mapping the Linkages a Scoping Study on Knowledge and Gaps\|.Report Prepared for the UK's Department for International Development (DFID) and Institute of Development Studies (IDS). Brighton: University of Sussex.

Dabbs, Jr, J. M., and H. Leventhal. 1966. "Effects of Varying the Recommendations in a FearArousing Communication." Journal of Personality and Social Psychology 4 (5): 525-531.

Fahmi, Z., B. A. Samah, and H. Abdullah. 2013. "Rice Industry and Rice Farmers Well-being: A Success Recipe for Agriculture Industry in Malaysia.” Asian Social Science 9 (3): 177.

Firdaus, R. R., I. A. Latiff, and P. Borkotoky. 2013. "The Impact of Climate Change Towards Malaysian Paddy Farmers." Journal of Development and Agricultural Economics 5 (2): 57-66.

Georgescu, M., D. B. Lobell, and C. B. Field. 2011. "Direct Climate Effects of Perennial Bioenergy Crops in the United States." Proceedings of the National Academy of Sciences 108 (11): 43074312.

Hair, J. F., W. C. Black, B. J. Babin, R. E. Anderson, and R. L. Tatham. 1998. Multivariate Data Analysis (Vol. 5, No. 3, 207-219). Upper Saddle River, NJ: Prentice Hall.

Hass, J. W., G. S. Bagley, and R. W. Rogers. 1975. "Coping with the Energy Crisis: Effects of Fear Appeals Upon Attitudes Toward Energy Consumption.” Journal of Applied Psychology 60 (6): 754-756.

Hertel, T. W., M. B. Burke, and D. B. Lobell. 2010. “The Poverty Implications of Climate-induced Crop Yield Changes by 2030.” Global Environmental Change 20 (4): 577-585.

IPCC, 2001. Climate Change 2001: Impacts, Adaptation, and Vulnerability. Intergovernmental Panel on Climate Change. Cambridge, UK: Cambridge University Press.

Kaldor, N. 1967. Strategic Factors in Economic Development. Ithaca, NY: Cornell University Press.

Kline, R. B. 2010. Principles and Practice of Structural Equation Modeling. 3rd ed. New York: Guilford Press.

Kruglanski, A. W., and W. Stroebe. 2005. "The Influence of Beliefs and Goals on Attitudes: Issues of Structure, Function, and Dynamics." In The Handbook of Attitudes, edited by Albarracín, D., B. T. Johnson, and M. P. Zanna. Abingdon: Routledge. Accessed 26 Feb 2018, Routledge Handbooks Online.

Le Dang, H., E. Li, J. Bruwer, and I. Nuberg. 2014. "Farmers' Perceptions of Climate Variability and Barriers to Adaptation: Lessons Learned from an Exploratory Study in Vietnam." Mitigation and Adaptation Strategies for Global Change 19 (5): 531-548. 
Leiserowitz, A. A., E. W. Maibach, C. Roser-Renouf, N. Smith, and E. Dawson. 2013. “Climategate, Public Opinion, and the Loss of Trust." American Behavioral Scientist 57 (6): 818-837.

Leventhal, H., R. Singer, and S. Jones. 1965. "Effects of Fear and Specificity of Recommendation Upon Attitudes and Behavior." Journal of Personality and Social Psychology 2 (1): 20.

Liverani, A. 2009. "Climate Change and Individual Behavior: Considerations for Policy." Policy Research Working Paper; No. WPS 5058. Washington, DC: World Bank.

Lobell, D. B., W. Schlenker, and J. Costa-Roberts. 2011. "Climate Trends and Global Crop Production Since 1980." Science 333 (6042): 616-620.

Lowry, P. B., and J. Gaskin. 2014. "Partial Least Squares (PLS) Structural Equation Modeling (SEM) for Building and Testing Behavioral Causal Theory: When to Choose It and How to Use It." Professional Communication, IEEE Transactions On, 57 (2): 123-146.

Maddison, D. 2007. "The Perception of and Adaptation to Climate Change in Africa." Policy Research Working Paper, No. 4308. Washington, DC: World Bank.

Malaysia. 2011. Tenth Malaysia Plan 2011-2015. Putrajaya: Government Printers.

Malhotra, N., and D. Birks. 2006. An Applied Approach, Marketing Research (3rd ed.). Georgia Institute of Technology: Pearson Education Ltd. Retrieved 2018, from http://catalogue.pears oned.co.uk/educator/product/Marketing-ResearchAn-Applied-Approach/0273706896.page

Man, N., and S. I. Sadiya. 2009. "Off-farm Employment Participation Among Rice Farmers in the Muda Agricultural Development Authority and Kemasin Semerak Granary Areas of Malaysia." Asia-Pacific Development Journal 16 (2): 141-153.

Marquit, J. D. 2008. “Threat Perception as a Determinant of Pro-Environmental Behaviors: Public Involvement in Air Pollution Abatement in Cache Valley, Utah." All Graduate Theses and Dissertations. 188. https://digitalcommons.usu.edu/etd/188.

Masud, M. M., R. Akhtar, R. Afroz, A. Q. Al-Amin, and F. B. Kari. 2015. "Pro-Environmental Behavior and Public Understanding of Climate Change." Mitigation and Adaptation Strategies for Global Change 20 (4): 591-600.

Masud, M. M., A. Q. Al-Amin, H. Junsheng, F. Ahmed, S. R. Yahaya, R. Akhtar, and H. Banna. 2016. "Climate Change Issue and Theory of Planned Behaviour: Relationship by Empirical Evidence." Journal of Cleaner Production 113: 613-623.

Masud, M. M., M. S. Rahman, A. Q. Al-Amin, F. Kari, and W. Leal Filho. 2014. "Impact of Climate Change: An Empirical Investigation of Malaysian Rice Production." Mitigation and Adaptation Strategies for Global Change 19 (4): 431-444.

Masutomi, Y., K. Takahashi, H. Harasawa, and Y. Matsuoka. 2009. "Impact Assessment of Climate Change on Rice Production in Asia in Comprehensive Consideration of Process/Parameter Uncertainty in General Circulation Models." Agriculture, Ecosystems \& Environment 131(3): 281-291.

McCown, R. L. 2005. "New Thinking About Farmer Decision Makers." In The Farmer's Decision: Balancing Economic Successful Agriculture Production with Environmental Quality, edited by Hatfield, J. L, 11-44. Ankeny, IA: Soil and Water Conservation Society.

NAHRIM, 2006. Final Report: Study of the Impact of Climate Change on the Hydrologic Regime and Water Resources of Peninsular Malaysia. Kuala Lumpur, Malaysia: NAHRIM.

Novelli, M., and A. Scarth. 2007. "Tourism in Protected Areas: Integrating Conservation and Community Development in Liwonde National Park (Malawi).” Tourism and Hospitality Planning \& Development 4 (1): 47-73.

NRS, 2001. National Response Strategies to Climate Change. Putrajaya, Malaysia: Ministry of Science, Technology and the Environment.

Patt, A. G., and D. Schröter. 2008. "Perceptions of Climate Risk in Mozambique: Implications for the Success of Adaptation Strategies." Global Environmental Change 18 (3): 458-467.

Rasiah, R. 1993. "Capitalist Industrialization in ASEAN." Journal of Contemporary Asia 24 (2): 197-216.

Rasiah, R. 2011. "Is Malaysia Facing Negative Deindustrialization.” Pacific Affairs 84 (4): 715-736.

Rogers, R. E., T. I. Bardsley, S. J. Weinstein, and B. J. Landi. 2011. "Solution-Phase Adsorption of 1Pyrenebutyric Acid Using Single-Wall Carbon Nanotubes.” Chemical Engineering Journal 173 (2): 486-493. 
Rosegrant, M. W., J. Koo, N. Cenacchi, C. Ringler, R. D. Robertson, M. Fisher, and P. Sabbagh. 2014. "Food Security in a World of Natural Resource Scarcity: The Role of Agricultural Technologies." Washington, DC: Intl Food Policy Res Inst.

Rubenstein, J. M. 2003. The Cultural Landscape: An Introduction to Human Geography. 7th ed., p. 496. Upper Saddle River, NJ: Pearson Education, Inc.

Sekaran, U. 2003. Research Methods for Business: A Skill-Building Approach. New York: John Willey and Son Inc.

Shome, D., S. Marx, K. Appelt, P. Arora, R. Balstad, K. Broad, A. Freedman, M. Handgraaf, D. Hardisty, D. Krantz and A. Leiserowitz. 2009. The Psychology of Climate Change Communication: A Guide for Scientists, Journalists, Educators, Political Aides, and the Interested Public. New York: Center for Research on Environmental Decisions.

Sia, A. P., H. R. Hungerford, and A. N. Tomera. 1985. "Selected Predictors of Responsible Environmental Behavior: An Analysis.” The Journal of Environmental Education 17 (2): 31-40.

Simon, K. J., and A. Das. 1984. "An Application of the Health Belief Model Toward Educational Diagnosis for VD Education." Health Education Quarterly 11 (4): 403-418.

Smit, B., and O. Pilifosova. 2003. "Adaptation to Climate Change in the Context of Sustainable Development and Equity.” Sustainable Development 8 (9): 9.

Stern, P. C., and T. Dietz. 1994. "The Value Basis of Environmental Concern." Journal of Social Issues 50 (3): 65-84.

Tubiello, F. N., and C. Rosenzweig. 2008. "Developing Climate Change Impact Metrics for Agriculture." Integrated Assessment 8 (1): 165-184.

Vaghefi, N., M. N. Shamsudin, A. Makmom, and M. Bagheri. 2011. The Economic Impacts of Climate Change on the Rice Production in Malaysia. International Journal of Agricultural Research 6 (1): 67-74.

Vaske, J. J., and K. C. Kobrin. 2001. "Place Attachment and Environmentally Responsible Behavior." The Journal of Environmental Education 32 (4): 16-21.

Vining, J., A. Ebreo, R. B. Bechtel, and A. Churchman. 2002. "Emerging Theoretical and Methodological Perspectives on Conservation Behaviour." Urbana 51: 61801.

Weiss, J. 2009. The Economics of Climate Change in Southeast Asia: A Regional Review. Asian Development Bank.

Witte, K. 1992. "Putting the Fear Back into Fear Appeals: The Extended Parallel Process Model." Communications Monographs 59 (4): 329-349.

Witte, K., 1998. "Fear as Motivator, Fear as Inhibitor: Using the Extended Parallel Process Model to Explain Fear Appeal Successes and Failures."

Yamane, T. 1967. Elementary Sampling Theory. Prentice-Hall. (No. 04; QA276. 5, Y3.). 